\title{
Video Article \\ The Three-Dimensional Human Skin Reconstruct Model: a Tool to Study Normal Skin and Melanoma Progression
}

\author{
Ling $\mathrm{Li}^{1}$, Mizuho Fukunaga-Kalabis ${ }^{1}$, Meenhard Herlyn ${ }^{1}$ \\ ${ }^{1}$ Molecular and Cellular Oncogenesis Program, The Wistar Institute \\ Correspondence to: Meenhard Herlyn at herlynm@wistar.org
}

URL: https://www.jove.com/video/2937

DOI: doi:10.3791/2937

Keywords: Bioengineering, Issue 54, 3D model, melanocyte, melanoma, skin

Date Published: 8/3/2011

Citation: Li, L., Fukunaga-Kalabis, M., Herlyn, M. The Three-Dimensional Human Skin Reconstruct Model: a Tool to Study Normal Skin and Melanoma Progression. J. Vis. Exp. (54), e2937, doi:10.3791/2937 (2011).

\section{Abstract}

Most in vitro studies in experimental skin biology have been done in 2-dimensional (2D) monocultures, while accumulating evidence suggests that cells behave differently when they are grown within a 3D extra-cellular matrix and also interact with other cells (1-5). Mouse models have been broadly utilized to study tissue morphogenesis in vivo. However mouse and human skin have significant differences in cellular architecture and physiology, which makes it difficult to extrapolate mouse studies to humans. Since melanocytes in mouse skin are mostly localized in hair follicles, they have distinct biological properties from those of humans, which locate primarily at the basal layer of the epidermis. The recent development of 3D human skin reconstruct models has enabled the field to investigate cell-matrix and cell-cell interactions between different cell types. The reconstructs consist of a "dermis" with fibroblasts embedded in a collagen I matrix, an "epidermis", which is comprised of stratified, differentiated keratinocytes and a functional basement membrane, which separates epidermis from dermis. Collagen provides scaffolding, nutrient delivery, and potential for cell-to-cell interaction. The 3D skin models incorporating melanocytic cells recapitulate natural features of melanocyte homeostasis and melanoma progression in human skin. As in vivo, melanocytes in reconstructed skin are localized at the basement membrane interspersed with basal layer keratinocytes. Melanoma cells exhibit the same characteristics reflecting the original tumor stage (RGP, VGP and metastatic melanoma cells) in vivo. Recently, dermal stem cells have been identified in the human dermis (6). These multi-potent stem cells can migrate to the epidermis and differentiate to melanocytes.

\section{Video Link}

The video component of this article can be found at https://www.jove.com/video/2937/

Protocol

\section{The Three-Dimensional Human Skin Reconstruct Model:}

1. Preparation of acellular layer: Mix the following reagents in a $50 \mathrm{~mL}$ tube on ice: $0.59 \mathrm{~mL} 10 \mathrm{X}$ EMEM, $50 \mu \mathrm{l} 200 \mathrm{mM} \mathrm{L-glutamine,} 0.6 \mathrm{~mL}$ FBS, $120 \mu \mathrm{l} 7.5 \%$ Sodium bicarbonate and $4.6 \mathrm{~mL}$ bovine collagen I. Add $1 \mathrm{~mL}$ of the mixture into each insert of tissue culture trays. Incubate for $30 \mathrm{~min}$ at room temperature and allow the gel to solidify. Color of the mixture should be from straw-yellow to pink.

2. Trypsinize human fibroblasts from culture flasks with $0.25 \%$ trypsin/EDTA, add DMEM containing $10 \%$ FBS to neutralize. Collect cells by centrifugation and resuspend $0.45 \times 10^{6}$ cells in $1.5 \mathrm{~mL}$ DMEM with $10 \%$ FBS. For dermal stem cells, collect 6600 dermal spheres (when dermal stem cells grow in stem cell medium, they form spheres in a similar manner to neurospheres) by tapping flask to detach the spheres, centrifugation.

3. Preparation of cellular layer: Mix the following in a $50 \mathrm{~mL}$ tube on ice: $1.65 \mathrm{~mL}$ 10X EMEM, $150 \mu \mathrm{l} 200 \mathrm{mM} \mathrm{L-glutamine,} 1.85 \mathrm{~mL}$ FBS, $350 \mu \mathrm{l}$ $7.5 \%$ Sodium bicarbonate, $14 \mathrm{~mL}$ bovine collagen I and $1.5 \mathrm{~mL}$ fibroblasts suspension from step 2 (alternatively, use combination of $0.45 \mathrm{x}$ $10^{6}$ fibroblasts and 6600 dermal spheres in $1.5 \mathrm{~mL}$ of skin reconstruct medium I for dermal stem cell reconstructs), mix well. Add $3 \mathrm{~mL}$ of the mixture to each acellular layer-coated insert. Incubate for $45 \mathrm{~min}$ at $37^{\circ} \mathrm{C}$ in a $5 \% \mathrm{CO}_{2}$ tissue culture incubator. Color of the mixture should be from straw yellow to pink. After the gel solidifies, add DMEM containing $10 \%$ FBS ( $2 \mathrm{~mL}$ inside and $10 \mathrm{~mL}$ outside of insert in each well of skin reconstruct trays). Incubate for 4 days and make sure that the gel contracts.

4. Aspirate medium from both inside and outside of each insert. Add washing medium (HBSS with $1 \%$ dialyzed FBS) $2 \mathrm{~mL}$ to the inside and 10 $\mathrm{mL}$ to the outside of insert in order to wash off regular serum. Incubate for 1 hour at $37^{\circ} \mathrm{C}$.

5. Preparation of skin reconstruct medium:

1. For normal melanocyte and dermal stem cell reconstructs: To make basic medium $(500 \mathrm{~mL})$, mix the following reagents: $490 \mathrm{~mL}$ keratinocyte serum-free medium, $1.8 \mathrm{~mL}$ bovine pituitary extract, $10 \mathrm{~mL}$ dialyzed fetal bovine serum, $500 \mu \mathrm{l}$ of $10 \mu \mathrm{g} / \mathrm{mL} \mathrm{SCF}, 562.5 \mu \mathrm{l}$ of $4 \mu \mathrm{g} / \mathrm{mL}$ bFGF and $500 \mu \mathrm{l}$ of $264 \mu \mathrm{g} / \mathrm{mL}$ ET-3. Medium I: Add $10 \mu \mathrm{l} \mathrm{EGF} \mathrm{of} 100 \mu \mathrm{g} / \mathrm{mL}$ to $100 \mathrm{~mL}$ basic medium. Medium II: Add $2 \mu \mathrm{l}$ EGF to $100 \mathrm{~mL}$ basic medium. Medium III: Add $720 \mu \mathrm{l} \mathrm{CaCl}$ of $1 \mathrm{M}$ to $300 \mathrm{~mL}$ basic medium.

2. For melanoma skin reconstruct: To make Medium I (100mL), mix the following reagents: $72.5 \mathrm{~mL}$ of DMEM, $24 \mathrm{~mL}$ of F12 (HAM's), 2 $\mathrm{mL}$ L-glutamine of $200 \mathrm{mM}, 200 \mu \mathrm{l}$ hydrocortisone of $269 \mu \mathrm{g} / \mathrm{mL}, 200 \mu \mathrm{l} \mathrm{ITES}$ of 500X, $200 \mu \mathrm{l}$ O-phosphorylethanolamine of $0.05 \mathrm{M}$, $200 \mu \mathrm{l}$ adenine of $90 \mathrm{mM}, 200 \mu \mathrm{l}$ Progesterone of $2 \mathrm{nM}, 240 \mu \mathrm{l} \mathrm{CaCl}{ }_{2}$ of $1 \mathrm{M}, 200 \mu \mathrm{l}$ Triiodothyronine of $10 \mathrm{nM}$ and $100 \mu \mathrm{l}$ of chelexed 
newborn calf serum (dissolve $3 \mathrm{~g}$ of Chelex $100 \mathrm{in} 100 \mathrm{~mL}$ of serum, stir 1.5 hours at $4{ }^{\circ} \mathrm{C}$, filter sterilize). To make Medium II (100mL), mix the following reagents: $72.5 \mathrm{~mL}$ of DMEM, $24 \mathrm{~mL}$ of F12 (HAM's), $2 \mathrm{~mL}$ L-glutamine of $200 \mathrm{mM}, 200 \mu \mathrm{l}$ hydrocortisone of $269 \mu \mathrm{g} /$ $\mathrm{mL}, 200 \mu \mathrm{l}$ ITES of $500 \mathrm{X}, 200 \mu \mathrm{l}$ O-phosphorylethanolamine of $0.05 \mathrm{M}, 200 \mu \mathrm{l}$ adenine of $90 \mathrm{mM}, 200 \mu \mathrm{l}$ Progesterone of $2 \mathrm{nM}, 240$ $\mu \mathrm{l} \mathrm{CaCl} 2$ of $1 \mathrm{M}, 200 \mu \mathrm{l}$ Triiodothyronine of $10 \mathrm{nM}$ and $100 \mu \mathrm{l}$ newborn calf serum. To make Medium III ( $300 \mathrm{~mL}$ ), mix the following reagents: $142.5 \mathrm{~mL}$ of DMEM, $142.5 \mathrm{~mL}$ of F12 (HAM's), $6 \mathrm{~mL}$ of L-glutamine of $200 \mathrm{mM}, 600 \mu \mathrm{l}$ hydrocortisone of $269 \mu \mathrm{g} / \mathrm{mL}, 600 \mu \mathrm{l}$ ITES of 500X, $600 \mu \mathrm{l}$ O-phosphorylethanolamine of $0.05 \mathrm{M}, 600 \mu$ ladenine of $90 \mathrm{mM}, 600 \mu$ l Progesterone of $2 \mathrm{nM}, 720 \mu \mathrm{l} \mathrm{CaCl}{ }_{2}$ of 1 $\mathrm{M}, 600 \mu \mathrm{l}$ Triiodothyronine of $10 \mathrm{nM}$ and $6 \mathrm{~mL}$ newborn calf serum.

6. Trypsinize human keratinocytes from culture flasks with $0.05 \%$ trypsin/EDTA, neutralize trypsin with soy bean trypsin inhibitor ( $250 \mathrm{mg} / \mathrm{L}$ in $1 \mathrm{x}$ phosphate buffered saline), spin down, resuspend a cell pellet at $4.17 \times 10^{6} \mathrm{cells} / \mathrm{mL}$ in skin reconstruct medium I.

7. Trypsinize human melanocytes or melanoma cells from culture flasks with $0.05 \%$ trypsin/EDTA, neutralize trypsin with soy bean trypsin inhibitor, spin down, resuspend a cell pellet at $0.83 \times 10^{6}$ cells $/ \mathrm{mL}$ in skin reconstruct medium I.

8. Remove washing medium from both inside and outside of each insert.

9. Add skin reconstruct medium I ( $1.5 \mathrm{~mL}$ to the inside and $10 \mathrm{~mL}$ to the outside of each insert).

10. Take $600 \mu \mathrm{l}$ cell suspension of keratinocytes and $600 \mu \mathrm{l}$ cell suspension of melanocytes or melanoma cells, mix well. Dispense $200 \mu \mathrm{l}$ mixed cell suspension drop by drop to the inside of each insert. For dermal stem cell reconstruct, use $100 \mu l$ of keratinocyte suspension only. Incubate for 2 days at $37^{\circ} \mathrm{C}$.

11. Aspirate skin reconstruct medium I from both the inside and the outside of each insert. Add skin reconstruct medium II $(2 \mathrm{~mL}$ to the inside and $10 \mathrm{~mL}$ to the outside). Incubate for another 2 days at $37^{\circ} \mathrm{C}$.

12. Aspirate skin reconstruct medium II from the inside and the outside of each insert, add $7.5 \mathrm{~mL}$ skin reconstruct medium III to only the outside. From this point, the surface of reconstructs starts being exposed to the air. Change medium III every other day until day 18.

13. Harvest skin reconstruct at day 18:

1. Aspirate media from the inside and the outside of inserts.

2. Remove inserts from tray with forceps.

3. Cut out the reconstruct (including the polycarbonate filter) by tracing a circle close to the edge with a scalpel blade.

4. Cut the reconstruct and the filter in half on a hard surface.

14. For paraffin sections: place a half of the reconstruct in a histology cassette between 2 black TBS biopsy papers and soak the whole cassette in $10 \%$ formalin for more than 4 hours. Then place the cassette in $70 \%$ ethanol and store it at $4{ }^{\circ} \mathrm{C}$ until you are ready to process the reconstruct for paraffin embedding.

15. For frozen sections:

1. Place the other half of reconstruct in $50 \%$ sucrose at $4{ }^{\circ} \mathrm{C}$ for $1-2$ hours, then change the sucrose to $2 \mathrm{M}$ and store it at $4{ }^{\circ} \mathrm{C}$ for another 1-2 hours.

2. Dispense optimal cutting temperature freezing media (OCT) into a disposable base mold so that it fills about $50 \%$ of the boat. Avoid any bubbles in the OCT.

3. Grab the edge of the reconstruct with forceps and remove the reconstruct from the sucrose. Place it on Kimwipes until the Kimwipes absorb the sucrose.

4. Transfer the reconstruct into the base mold on top of the OCT, using forceps and a spatula. Cover the top of the reconstruct with more OCT until the base mold is completely full. Make sure you do not have any bubbles in the OCT which will make cutting difficult.

5. Place the base mold evenly on crushed dry ice, and allow the OCT to freeze completely.

6. Wrap the base mold in tin foil and store it at $-70^{\circ} \mathrm{C}$ until you are ready to cut it with a cryostat.

16. Graft a skin reconstruct on a mouse:

1. Prepare a $50 \mathrm{~mL}$ falcon tube with $5 \mathrm{~mL}$ of DMEM (for freezing and defrosting mouse skin).

2. Use a female SCID hairless outbred mouse around 6 weeks.

3. The mouse is anesthetized with isoflurane ( $E Z$ anesthesia system): initial anesthesia is performed in the induction chamber with $4 \%$ isoflurane (before mouse is moved to the surgical bed) and maintain anesthesia through a nosecone breather during procedure (isoflurane: $1.5-2 \%$ ). Heat support by a heated pad to prevent hypothermia and sterile ophthalmic lubricant applied to prevent ocular injury during anesthesia.

4. Put $600 \mathrm{~mL}$ water in a beaker and leave on top of a hot plate to keep water temperature between $40-60{ }^{\circ} \mathrm{C}$.

5. Clean the mouse skin with compound benzoin tincture and alcohol prep swabs.

6. Mark a line on top of the mouse back to keep the same position for suturing later.

7. Cut a round wound bed about $1.2 \mathrm{~cm}$ in diameter on the mouse upper back using Iris scissors and forceps. Cover the wound bed with sterile gauze sponges. Put the round mouse skin in $5 \mathrm{~mL}$ of DMEM, then leave in liquid nitrogen container until it totally frozen. Defrost the tube in hot water on top of a hot plate until totally thawed. Repeat 3 times.

8. Detach the skin reconstruct from the transwell using surgical blade and remove the membrane very carefully, transfer the skin reconstruct (epidermis side up) on top of the wound bed.

9. Place the mouse skin (epidermis side up) on top of the skin reconstruct.

10. Make the first suture on the marker previously labeled, the second on the bottom, then two more sutures on sides to fix the mouse skin.

11. Clean mouse skin after grafting. Remove nosecone and keep mouse on the heated pad until awake and ambulatory.

12. Put the mouse into a new cage.

13. Post operative analgesia: Meloxicam $(1 \mathrm{mg} / \mathrm{kg}$ ) by subcutaneous injection immediately after surgery, 24 hours and 48 hours after surgery.

\section{Representative Results:}

Skin reconstructs with normal melanocytes and dermal stem cells

The skin reconstructs are cultured in a special 6-well tray with inserts. The dermal compartment is cultured in DMEM with $10 \%$ FBS for the first four days (Fig. 1A). The skin reconstruct medium I is used when keratinocytes are seeded with melanocytes or melanoma cells (Fig. 1B). The 
epidermis is exposed to the air at day 9 and this allows keratinocytes to differentiate (Fig. 1C). At day 18, the epidermis of skin reconstructs is composed of stratified keratinocyte layers. The undifferentiated basal layer and sequentially differentiated layers are vertically oriented (Fig. 1D). Staining the section of reconstructs with the melanocytic marker S100 shows that melanocytes are aligned in the basal layer of the epidermis and communicate with multiple keratinocytes through dendrite extensions (Fig. 1E). The dermal compartment contains fibroblasts embedded in a collagen type I matrix. Deposited collagen IV indicates the basement membrane, which separates the epidermis from the dermis (Fig. 1F). When dermal stem cells (labeled with GFP lentiviral vector) are embedded with fibroblasts in a collagen I matrix, they migrate to the epidermis and differentiate into melanocytes (1), (Fig. 2). Multiple layers of keratinocytes in the epidermis are developed.

Skin reconstructs of melanoma tumors

Clinicopathological studies indicate that melanomas progress in a stepwise manner: common acquired nevi, dysplastic nevi, RGP (radial growth phase) melanomas, VGP (vertical growth phase) melanomas and metastatic melanomas (7). Different stages of melanoma cell lines are morphologically similar to each other in 2-D culture (Fig. 3A-D) but when they are incorporated in skin reconstructs, the behavior of the cells reflects their in vivo characteristics. The location and the growth rate of normal melanocytes are tightly controlled in skin reconstructs (Fig. 3E). RGP primary melanomas WM35 proliferate predominantly in the epidermis (Fig. 3F), whereas VGP melanomas WM793 grow invasively into the dermis (Fig. 3G). Metastatic melanomas 1205Lu aggressively invade deep into the dermis (Fig. 3H).
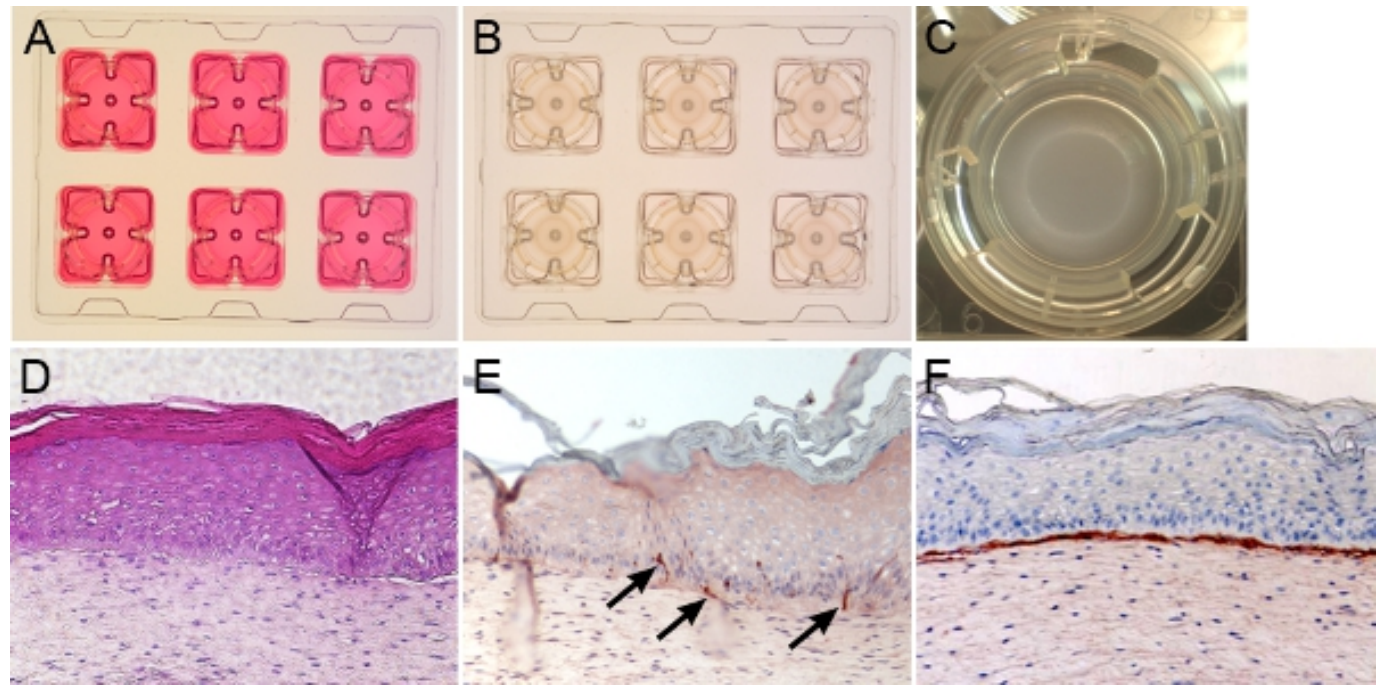

Figure 1. Skin reconstructs with normal melanocytes. The gross appearance of the skin reconstructs is shown in A-C. A. Fibroblasts mixed with collagen are grown in DMEM containing 10\% FBS and form dermal compartment. B. Keratinocytes and melanocytes are seeded on top of the dermis and grow in skin reconstruct medium. C. The epidermis is exposed to air at day 9. D. H\&E-stained skin reconstruct presents the epidermis comprised vertically, oriented basal layer, and sequentially differentiated stratified cell layers. The dermis contains fibroblasts embedded in a collagen type I matrix. E. S100-positive melanocytes (black arrows) are aligned at the basement membrane and communicate with multiple keratinocytes. F. Collagen IV-staining indicates the basement membrane, which separates the epidermis from the dermis. All the stainings in D-F were performed on formalin-fixed, paraffin-embedded sections.
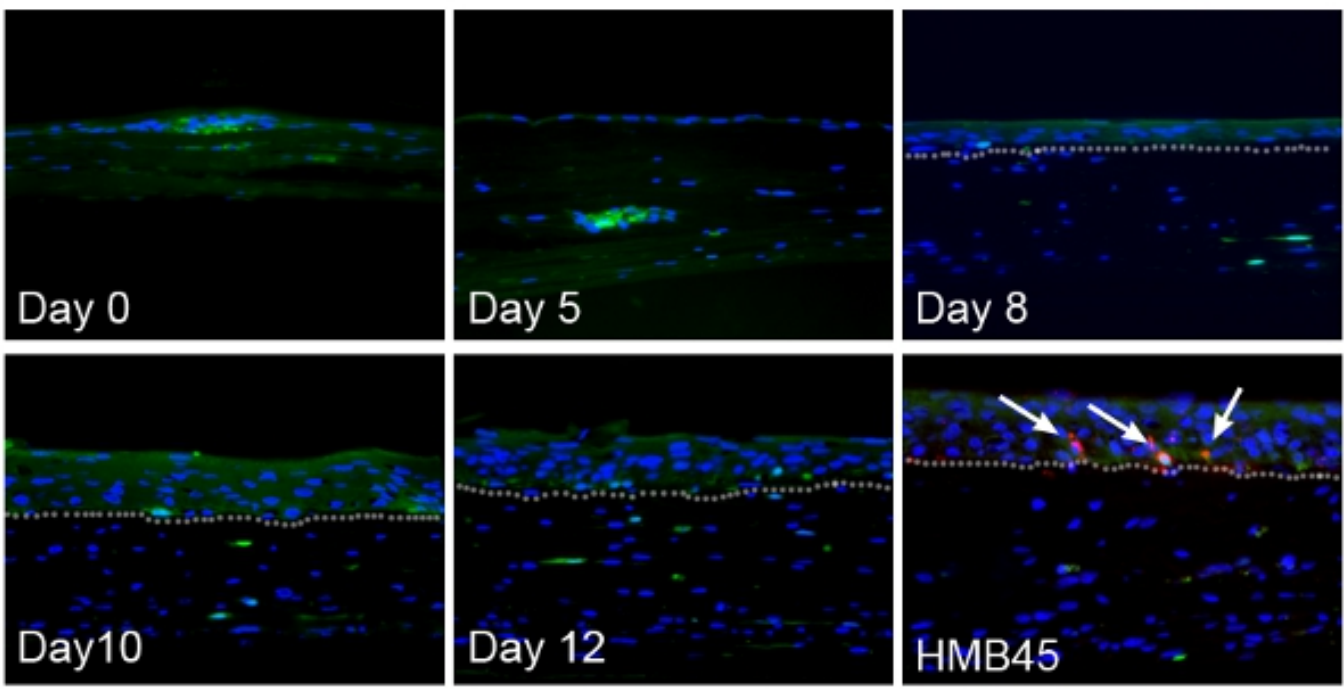

Figure 2. Dermal stem cells in skin reconstructs migrate to the epidermis and differentiate into melanocytes. At day 5 after seeding keratinocytes, single GFP-positive cells (green) start migrating out from spheres. The epidermis is still composed of a single layer. At day 8 , a few cells reach the epidermis-dermis interface. By day 10, GFP-positive cells are tightly aligned at the basement membrane position. The 
migrated GFP-positive cells in the epidermis express melanocytic marker HMB45 (red, as indicated by white arrows). Nuclei are stained with DAPI (blue). The epidermis is developed as multiple layers. The basement membrane is indicated with white dotted lines.

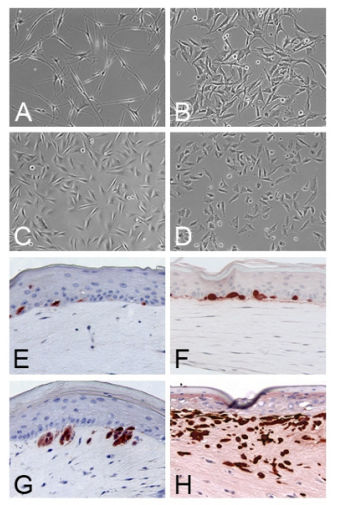

Figure 3. Skin reconstructs of different stages of melanomas: A-D. Normal melanocytes and melanoma cells grown in 2D cultures. A. Melanocytes from foreskin. B. RGP WM35 cells. C. VGP WM793 cells. D. Metastatic melanoma 1205Lu cells. E. Normal melanocytes are located at the basement membrane. F. RGP melanoma WM35 cells grow as cell clusters in the epidermis. G. VGP melanoma WM793 cells invade into the dermis through basement membrane. H. Metastatic melanoma 1205Lu cells aggressively invade deep into dermis.

\section{Troubleshooting}

\begin{tabular}{|l|l|}
\hline Problem & Troubleshooting \\
\hline Collagen mixture does not solidify & $\begin{array}{l}\text { Collagen mixture color should be straw-yellow to pink, otherwise pH } \\
\text { is wrong and collagen may not gel. If the color is bright yellow, more } \\
\text { sodium bicarbonate should be added drop by drop. }\end{array}$ \\
\hline Collagen prematurely precipitates in the mixuture & $\begin{array}{l}\text { Keep all components on ice until the collagen mixture is placed onto the } \\
\text { insert }\end{array}$ \\
\hline Contracted collagen is not even (one side is thicker than the other side) & Calibrate the shelf of incubator \\
\hline The epidermis is formed with less than three keratinocyte layers. & Use undifferentiated keratinocytes at lower passages \\
\hline
\end{tabular}

\section{Discussion}

We have described generating 3D skin reconstructs with normal human melanocytes, dermal stem cells and melanoma cells. When grown in monolayer culture, melanocytic cells present a similar morphology (flattened, spindle or more dendritic-shaped) regardless of their origin of clinical stage. In contrast, 3D skin reconstructs recapitulate stage-specific properties of melanoma cells. Normal human melanocytes reside at the basement membranes between the epidermal and the dermal layers as single cells. RGP primary melanoma cells grow as small clusters along the basement membrane whereas more aggressive VGP melanoma cells grow as large clusters breaking through the basement membrane into the dermis. Metastatic melanoma cells grow in all directions and invade deep into the dermis as single cells or clusters. Quantitative analyses can be performed on this model by measuring the depth of invasion and the extent of proliferation. In addition to characterization of normal and malignant melanocytic cells, using the model we can directly induce the differentiation of dermal stem cells into matured melanocytes, which home to the basal layer of epidermis and establish bona fide communication with keratinocytes through upregulation of E-cadherin (6).

Using viral vectors, we are able to either activate or inactivate gene function for a better understanding of the dynamics and functional significance of genes expressed by each cell type in skin reconstructs, which promises to be an efficient model to study not only transformation mechanisms of melanocytes, but also progression of melanoma (8). Long-term observation of cell phenotypes has become possible through grafting of skin reconstructs to immunodeficient animals. Such a human skin-mouse chimera is an excellent research tool to study melanomagenesis and melanoma metastasis.

Skin reconstructs can also be a useful platform for drug assessment. Many drugs which eradicate cancer cells in 2D culture conditions often have little effect in experimental and clinical applications. As seen in the in vivo tumor, melanoma cells in 3D cultures are often resistant to the drugs which cells in 2D cultures respond to, suggesting that the microenvironment modulates signaling pathways in melanoma. For successful drug discovery, the 3D skin reconstruct model is an ideal preclinical tool to predict the effects of compounds in vivo $(9,10)$.

In summary, skin reconstruct models bridge the gap between in vitro and in vivo studies. They will lead to a better understanding of which genes are involved in transformation and how stem cells contribute to that transformation.

\section{Disclosures}

No conflicts of interest declared. 


\section{Acknowledgements}

We thank the Wistar Institute Animal Facility, Microscopy Facility, Histotechnology Facility and Research Supply Center. This study was funded in part by grants from the National Institutes of Health CA 076674, CA 098101, CA 025874 and CA 10815.

\section{References}

1. Sun, T., Jackson, S., Haycock, J.W., \& MacNeil, S. Culture of skin cells in 3D rather than 2D improves their ability to survive exposure to cytotoxic agents. J Biotechnol. 122 (3), 372-81 (2006).

2. Smalley, K.S., Lioni, M., \& Herlyn, M. Life isn't flat: taking cancer biology to the next dimension. In Vitro Cell Dev Biol Anim. 42 (8-9), 242-7 (2006).

3. Sun, T., Norton, D., McKean, R.J., Haycock, J.W., Ryan, A.J., \& MacNeil, S. Development of a 3D cell culture system for investigating cell interactions with electrospun fibers. Biotechnol Bioeng. 97 (5), 1318-28 (2007).

4. Kremer, M., Lang, E., \& Berger, A. Organotypical engineering of differentiated composite-skin equivalents of human keratinocytes in a collagen-GAG matrix (INTEGRA Artificial Skin) in a perfusion culture system. Langenbecks Arch Surg. 386 (5), $357-63$ (2001).

5. Escámez, M.J., García, M., Larcher, F., Meana, A., Muñoz, E., Jorcano, J.L. \& Del Río, M. An in vivo model of wound healing in genetically modified skin-humanized mice. J Invest Dermatol. 123 (6), 1182-91 (2004).

6. Li, L., Fukunaga-Kalabis, M., Yu, H., Xu, X., Kong, J., Lee, J.T., \& Herlyn, M. Human dermal stem cells differentiate into functional epidermal melanocytes. J Cell Sci. 123, 853-860 (2010).

7. Meier, F., Nesbit, M., Hsu, M.Y., Martin, B., Van Belle, P., Elder, D.E., Schaumburg-Lever, G., Garbe, C., Walz, T.M., Donatien, P., Crombleholme, T.M., \& Herlyn, M. Human melanoma progression in skin reconstructs: biological significance of bFGF. Am J Pathol. 156(1), 193-200 (2000).

8. Yu, H., McDaid, R., Lee, J., Li, L., Kumar, S.M., Elder, D.E., Van Belle, P., Gimotty, P., Guerra, M., Hammond, R., Nathanson, K.L., Dalla Palma, M., Herlyn, M., \& Xu, X. The role of BRAF mutation and p53 inactivation during transformation of a subpopulation of primary human melanocytes. Am J Pathol. 174(6), 2367-77 (2009).

9. Lee, J.T., Li, L., Brafford, P.A., van den Eijnden, M., Halloran, M.B., Sproesser, K., Haass, N.K., Smalley, K.S., Tsai, J., Bollag, G., \& Herlyn, M. PLX4032, a potent inhibitor of the B-Raf V600E oncogene, selectively inhibits V600E-positive melanomas. Pigment Cell Melanoma Res. 23(6), 820-7, (2010).

10. Tsai, J., Lee, J.T., Wang, W., Zhang, J., Cho, H., Mamo, S., Bremer, R., Gillette, S., Kong, J., Haass, N.K., Sproesser, K., Li, L., Smalley, K.S., Fong, D., Zhu, Y.L., Marimuthu, A., Nguyen, H., Lam, B., Liu, J., Cheung, I., Rice, J., Suzuki, Y., Luu, C., Settachatgul, C., Shellooe, R., Cantwell, J., Kim, S.H., Schlessinger, J., Zhang, K.Y., West, B.L., Powell, B., Habets, G., Zhang, C., Ibrahim, P.N., Hirth, P., Artis, D.R., Herlyn, M., \& Bollag, G. Discovery of a selective inhibitor of oncogenic B-Raf kinase with potent antimelanoma activity. Proc Natl Acad Sci U S A. 105 (8), 3041-6 (2008). 